DOI: 10.32743/fun.app.probl.2021.97-106

\title{
Research on the Time Influence of Ultrasonic Impact on the Strength Characteristics of Joining the Parts of Summer Shoes
}

\author{
Guzel N. NURULLINA \\ Ph. D. (in Technical sciences) \\ Associate Professor \\ Faculty of Textile Industry Technology and Fashion, \\ Textile Industry Materials and Technologies Department \\ Kazan National Research Technological University \\ 68, Karl Marx Str., Kazan, 420015, Russia \\ nur.guthel@inbox.ru \\ Yuliya V. TEREKHINA \\ $\mathrm{Ph}$. D. (in Historical sciences) \\ Associate Professor \\ Faculty of Textile Industry Technology and Fashion, \\ Textile Industry Materials and Technologies Department \\ Kazan National Research Technological University \\ 68, Karl Marx Str., Kazan, 420015, Russia \\ yu-2300@mail.ru
}

\begin{abstract}
The article tackles the problem of modern polymer materials and ultrasonic coupling application in footwear industry. During the study of ultrasonic connections of shoe parts it turned out that the low strength of the seams is an important problem. The purpose of the study is to increase the strength characteristics of the ultrasonic connections of summer shoe parts. Ethylene vinyl acetate, medium and low-density polyurethane, as well as belt tape that are used in summer shoes manufacture, were used as research objects. The study was carried out with the use of standard methods and techniques for determining the breaking load, and breaking load in shear. The equipment of the materials and technologies of textile industry department of the Kazan national research technological University was used for the research. The experiments results showed the influence of one of the main parameters of ultrasonic welding. The results of strength tests of the obtained samples allowed us to conclude that, in the area of sound waves impact of on the materials' welding process used in shoe production, the optimal mode is the action of an ultrasonic wave for 3 seconds in the preliminary fastening.
\end{abstract}

Keywords: footwear; polyurethane; ethylene vinyl acetate; ultrasound; strength.

\section{Introduction}

Fashion is often treated as entertainment, but it also reflects the problems of the modern world. The current season trends are moving in two directions: the pursuit of timeless values and the need for protection. Both trends are a consequence of difficult economic and social situation in the world. Shoes play the most direct role in every person's life. More than that, shoes are aesthetic. The type of footwear often complements and emphasizes a person's appearance. Therefore, it is important to be able to choose according not only visual, but also qualitative characteristics (Tsobkallo et.al, 2006). 
Every year people get more and more curious about new products in footwear industry. Let us consider the modern footwear models that imply new materials and technologies in their production.

High boots with a wide, straight tope have pointed toes and tapered heels, while they are soft enough to gather a little at the ankles. Stable and comfortable, the boots are responsible for a feminine yet confident gait.

Boots with high, stable heels also combine femininity and comfort. This season, the models are close to the ankles due to high lacing or soft leather.

Cowboy boots in the form of half boots and ankle boots in improved graphic versions, retain from the original form only an elongated pointed nose and a thick geometric heel (Nikitina et. al., 2012).

Thick soles with deep tread are one of the indicative trends in the quest for protection. Such a sole makes the shoes aggressive and brutal, while it can accompany not only rough shoes, but also models with high heels and lacing.

High-toed Chelsea boots also have chunky rubber tread soles that can be so large that make the boots look like astronaut ones (Nikitina et. al., 2012).

A trend that stands out for its relative novelty and extravagance is shoes with square toes. They define the geometry of ankle boots having wide square toes and pyramid-shaped heels, as well as pumps with elongated rectangular toes.

In new season it will be possible for sneakers' fans to show their originality thanks to striking models of technological design. These models are aerodynamic, showcase innovative technologies and emphasize the importance of athletic performance.

A huge variety of new products have entered the fashion world along with the last decade. Initially, high-tech materials were intended for the production of only one type of product, but gradually technology has moved to all related areas. Today extraordinary qualities of the latest materials are more and more manifested in everyday shoes. Excretion of sweat in an amount exceeding $150 \mathrm{~g} / \mathrm{h}$ is associated with thermal discomfort, which is taken into account in modern shoe materials (Schrobsdorff, 2006). Specific requirements are imposed on footwear are caused by the peculiarities of the use of products (Zhuravleva, 2011). An important task is to ensure full mobility of its owner without disrupting his physical capabilities (Iberall, 1964). One of the areas of research to improve ergonomic performance is the scientific approach (Marreiros, 2010; Newman et. al. 2003). The requirements for the footwear quality are growing faster and faster: it should not fade in the sun, be resistant to abrasion and "breathe", not change color during use, not let in moisture, etc. The footwear exterior also plays one of the most important roles here. The shoes are simply obliged to demonstrate the high quality of innovative materials. Therefore, more and more often, designers have to use even those raw materials that were originally intended for completely different purposes. Traditional and innovative materials are widely used in modern footwear production (Abutalipova et.al., 2018). The science progress has made it possible to introduce into production new generation high-polymer artificial materials that allow footwear to protect feet from various environmental factors perfectly and be highly wear-resistant. The use of new materials entails the development and implementation of modern technologies in production, since the traditional methods of joining shoe parts (adhesive, thread and combined) are not always effective (Ryazanov et. al. 2015, Iberall, 1964, Schrobsdorff, 2006).

The use of constant magnetic field at the stabilization stage of adhesive joint, the use of steam chemical active environment when preparing surfaces for bonding and at the stage of forming an adhesive joint, processing of low-temperature glow discharge plasma of the surfaces to be bonded are the new elements of the footwear manufacturing technological process. The methods using ultrasonic equipment occupy a special place in shoes making technology. However, a problem of 
reliable connection of the materials used insurance has been noticed when using ultrasonic welding of shoe parts.

The study of the ultrasonic connection mode parameters influence on summer shoe parts connection on the strength characteristics has aroused significant interest.

\section{Methods and Materials}

The use of polymeric materials in the manufacture of footwear makes it possible to change their properties over a wide range (Gavrilova et. al., 2013). For example, the use of polymer molded shoe soles makes it possible to shorten the production cycle by eliminating such operations as punching out parts, processing the sole ends, grinding, attaching the heel, etc. The use of EVA polymer material allows you to achieve the necessary lightness, softness and elasticity (Nikitina et. al., 2012). The use of complex materials in footwear production makes it possible to optimize the technological process: to exclude some operations of parts assembly, in-process wet-heat treatment, to reduce the time for lining and intermediate materials' cutting and their parts processing. At the same time, the use of polymeric materials makes it possible to improve the finished products' consumer properties.

Since the 30s of the last century, polymeric materials have been widely used in footwear industry. Polymeric materials have made it possible to use their properties in a wide range.

Thanks to the polymers used, the sole can have from one to three zones with different densities, which are adjusted during the process of pouring polyurethane into the intermediate layer. If the forefoot needs firm support, then the density of the sole there should be greater than in the soft heel. The greatest density is required for the shank part, located between heel and toe, so that it would not be possible to dislocate the leg. Several types of materials are used simultaneously: rubber and (in the running layer), reactive polyurethane (in the intermediate layer). Polyurethane makes it possible to add chemical components that affect density, hardness, rebound, compression set, flexibility and other characteristics of the outsole (Zhuravleva et.al., 2011)

Polymers are widely used in special footwear production. Attention to the footwear user's needs has led to the introduction of more modern and comfortable puncture protection systems. Composite toe cap as well as modern and comfortable puncture protection systems is a new word in safety footwear production. Inserts made of anti-puncture cloth as the most modern technologies in the field of ballistic protection equipment. Reliable protection is created by overlaying a dense net of very high strength polyester fibers that makes it possible to get a special layer that protects $100 \%$ of the foot surface, guaranteeing maximum comfort due to its light weight and flexibility.

At present, in our country, various types of polymers with various properties are being produced. They are often superior to some of the natural materials' properties (Marreiros, 2010).

The most common material is polyurethane (PU). It absorbs shock loads well, is quite wearresistant and also has a low cost. Polyurethane has a significant drawback its elasticity decreases at low temperatures. Such a sole is usually attached with an adhesive method.

An alternative material is thermopolyurethane (TPU). TPU is a wear-resistant material. It is a modern high-tech plastic, belonging to the class of constructional ones. It has outstanding strength indicators (even higher than that of polyester), increased wear resistance, excellent resistance to almost any natural and chemical influences, and hygroscopicity. TPU retains its working properties in a wide temperature range - from $-50^{\circ}$ to $+170^{\circ} \mathrm{C}$. The plastic's melting point exceeds $210^{\circ} \mathrm{C}$.

Almost complete absence of cracking tendency, high resistance to various kinds of deformations and excellent mechanical properties make thermopolyurethane one of the best for the manufacture of parts designed for severe operating conditions and the most severe power loads, with high requirements for reliability and durability. Initially, this type of plastic was created to replace metal 
(including steel) elements in the structures of various mechanisms and is comparable in its physical and mechanical properties to metals. Although its weight is 3-7 times less than that of metal.

Thermoplastic rubber (TPR) is also used as summer shoes' sole that is made from synthetic rubber/ Its strength characteristics are higher than that of natural rubber. Thermoplastic rubber outsole has got good shock absorption properties. Its distinctive features are lightness, moisture resistance and high thermal protection. It is especially good for children's shoes - thermoplastic rubber relieves unnecessary stress from the legs and spine. If such a sole is also embossed, it will be in close contact with the ground, preventing slipping (Newman et. al., 2003)

The modern polymer - ethylene vinyl acetate (EVA) has the following positive properties:

- soft, with shock-absorbing properties, porous structure, slightly rough to the touch;

- very light (more than 3 times lighter than polyvinyl chloride material, and accordingly rubber);

- good heat-shielding properties;

- hygiene, because it is resistant to bacteria and fungi.

However, ethylene vinyl acetate does not have frost resistance, it manifests itself especially well in summer sports, beach and medical footwear (Nikitina et. al., 2012).

Analyzing the polymeric materials' characteristics for the shoes' bottom, in the context of shoe production optimizing, the best material for summer shoes is a new polymeric material - ethylene vinyl acetate (EVA), as well as traditional polyurethane of various density (Gavrilova et. al. 2013).

The research objects for our scientific work were provided by the Taezhnik enterprise (Kazan), which specializes in the manufacture of products from ethylene vinyl acetate, polyurethane in combination with a belt band. These materials have a wide range of applications, are very light, elastic, environmentally friendly (do not emit any harmful substances, smell or interact with the environment); resistant to aggressive environments (anti-icing agents, salts, petroleum products, vegetable and industrial oils); 100\% waterproof. Besides, they have excellent shock absorption.

The following materials were selected as objects of our research: EVA and polyurethane foam of various densities (used for the summer shoes' soles) and a belt tape (used as the shoes' upper part).

Belt tape is a high-strength tape made of both natural and synthetic fibers. The combination of cotton fiber and artificial yarns with increased strength (polyamide, polystyrene, polyester fiber, etc.) makes it possible to obtain belt tapes (slings) that can withstand even very heavy loads. With the addition of a reflective element, the strap gains additional advantage that lets it be used where special precautions are required.

Belt and sling tapes can be used, depending on their material and breaking load, for the manufacture of collars and leashes, in sewing industry, when sewing awnings, etc., big bags, in the manufacture of tow cables, ties for securing loads, etc. The tape is widely used in the clothing industry - it is used to make handles for backpacks and bags, belts for trousers. Garment production is not complete without the use of edging tape. A variety of weaving options and colors allows you to choose a tape that is ideal for a particular thing. The use of the tape in the household is also varied from leashes and collars for dogs and ending with the manufacture of belay systems in industry and mountaineering. Two types of tapes are produced: edging slings that are irreplaceable in sewing industry and polypropylene slings that are distinguished by high wear resistance. Tapes for the manufacture of cargo slings must have an increased breaking load. Belt tape with a reflective element is used in the production of sportswear, children's, special worker's wear in order to highlight the contour of a person in the dark. The characteristics of the research objects are 
presented in Table 1. Ultrasonic connection was carried out on HANDY STAR 35kHz $1000 \mathrm{~W}$ equipment, China.

Table 1. Characteristics of research objects (Dolidze et. al. 2014)

\begin{tabular}{|c|c|c|c|c|}
\hline \multirow[b]{2}{*}{ Characteristic } & \multicolumn{4}{|c|}{ Material name } \\
\hline & $\begin{array}{c}\text { Ethylene Vinyl } \\
\text { Acetate }\end{array}$ & $\begin{array}{c}\text { Medium } \\
\text { Density } \\
\text { Polyurethane }\end{array}$ & $\begin{array}{l}\text { Low Density } \\
\text { Polyurethane }\end{array}$ & Tape \\
\hline Water absorption, $\%$ & 0.003 & 0.05 & 0.05 & - \\
\hline Fibrous composition, $\%$ & - & - & - & Nylon 100 \\
\hline Symbol & EVA & $\mathrm{P} / \mathrm{U}$ & $\mathrm{P} / \mathrm{U}$ & LR-25 \\
\hline Melting point, ${ }^{\circ} \mathrm{C}$ & 90 & $50-80$ & $50-80$ & - \\
\hline Thickness, mm & 15 & 15 & 15 & $2.1 \pm 0.2$ \\
\hline Breaking load, $\mathrm{N}$ & 30 & 27 & 20 & 1127.8 \\
\hline Breaking elongation, $\%$ & 35 & 35 & 35 & 18.0 \\
\hline Linear density, g / m & - & - & - & 34.0 \\
\hline Density, $\mathrm{kg} / \mathrm{m}^{3}$ & 20 & 35 & 25 & - \\
\hline
\end{tabular}

When performing the research, standard methods were used.

The study of strength characteristics was carried out in accordance with GOST ISO 17708-2014 "Shoes. Methods for testing finished footwear" on a Tenso-lab3 tensile testing machine (PC) manufacturer" Labthink Instruments Co, LTD ", China (Nurullina et. al., 2017, p, 31). The equipment has the ability to determine the following parameters: absolute and relative elongation, breaking load, tensile strength, single- and multi-cycle characteristics at uniaxial tension, elastic modulus, strength hysteresis, tensile strength, average tensile strength, tear strength of textile materials. The latter is controlled by a microcomputer and tests are performed automatically. The machine is equipped with a sensor that guarantees the measurement accuracy.

The sonication of the samples was carried out on an ultrasonic installation.

From the experiments' results, it is possible to establish the influence of the main parameters of the ultrasonic welding modes (pressing force, welding time) on the strength of the ultrasonic weld; as well as to trace the dependence of the welded seam strength on the time of ultrasound exposure.

All research was carried out in the laboratory of the Textile Industry Materials and Technologies Department.

\section{Results and Discussion}

As a result of the research, ultrasonic connections of the LR-25 tape with three polymer samples were performed, while the ultrasound exposure time varied from 2 to 3 seconds. The preliminary fastening of the tape was also carried out.

An important performance characteristic of footwear is the strength of the parts' connection. In laboratory conditions, the studies of the welded joint's strength characteristics were carried out breaking load, elongation at break and shear strength of the joint, the results are presented in Table 2 and Figures 1-3.

Table 2. The research of breaking load and elongation at break of a welded joint at different times of ultrasonic (US) welding 
Fundamental and applied problems of materials creation and phases of technologies for textile industry

\begin{tabular}{|c|c|c|c|c|c|}
\hline № & Name of the sample & Density, $\mathrm{kg} / \mathrm{m}^{3}$ & $\begin{array}{l}\text { Time of ultrasonic } \\
\text { welding, s. }\end{array}$ & Breaking load, H & $\begin{array}{c}\text { Elongation at } \\
\text { break, \% }\end{array}$ \\
\hline \multirow[t]{4}{*}{1} & \multirow{4}{*}{$\begin{array}{l}\text { Ethylene } \\
\text { acetate }\end{array}$} & \multirow[t]{4}{*}{20} & 2 & 25 & 36.80 \\
\hline & & & 3 & 16 & 31.20 \\
\hline & & & 3 & 27 & 25.60 \\
\hline & & & with pre-fastening & & \\
\hline \multirow[t]{4}{*}{2} & \multirow{4}{*}{$\begin{array}{l}\text { Low density } \\
\text { polyurethane }\end{array}$} & 25 & 2 & 13 & 32.80 \\
\hline & & & 3 & 10 & 50.00 \\
\hline & & & 3 & 20 & 74.80 \\
\hline & & & with pre-fastening & & \\
\hline \multirow[t]{4}{*}{3} & \multirow{4}{*}{$\begin{array}{l}\text { Medium density } \\
\text { polyurethane }\end{array}$} & \multirow[t]{4}{*}{35} & 2 & 12 & 37.60 \\
\hline & & & 3 & 7 & 29.60 \\
\hline & & & 3 & 19 & 40.40 \\
\hline & & & with pre-fastening & & \\
\hline
\end{tabular}

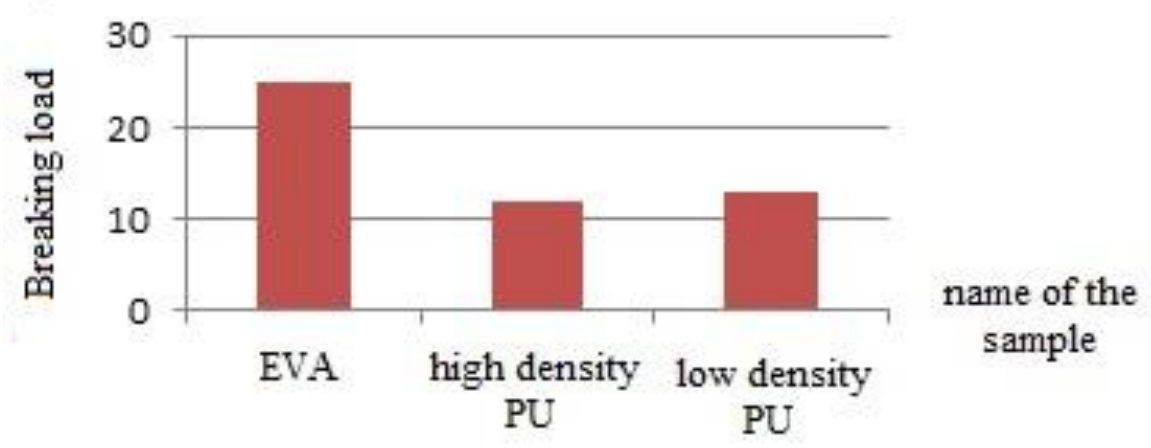

Figure 1. Results of breaking load indicators (with ultrasound exposure 2 seconds)

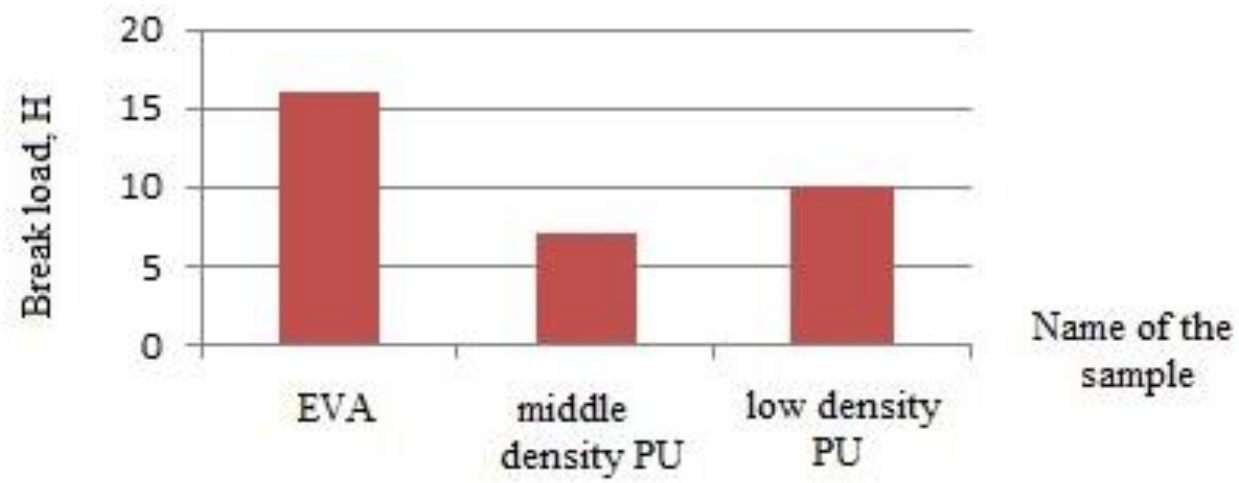

Figure 2. Results of breaking load indicators (with ultrasound exposure 3 seconds) 


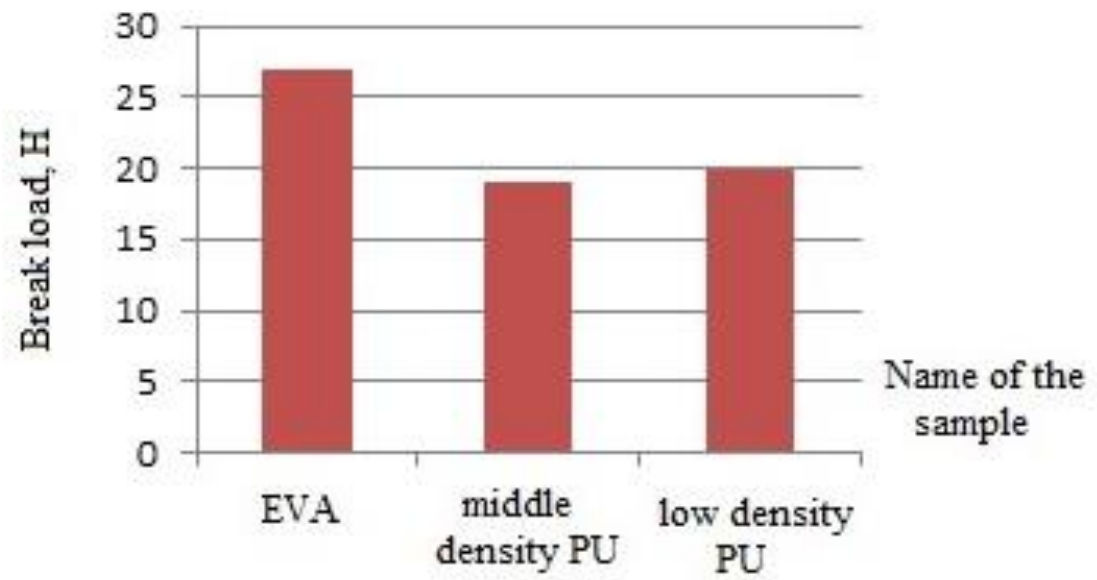

Figure 3. Results of breaking load indicators (with ultrasound exposure 2 seconds and with the use of pre-fastening)

Analysis of the research results showed that EVA, when exposed to an ultrasonic wave for 3 seconds with preliminary fastening, has a maximum breaking load of $27 \mathrm{~N}$. There is a cohesive fracture mechanism that shows higher strength indicators, while medium density polyurethane showed the lowest results $-19 \mathrm{~N}$.

Experimental results (elongation at break) showed that maximum elongation (74.8\%) was observed for the low-density polyurethane-to-tape bond (ultrasonic bonding is 3 seconds using pre-bonding), which indicates high elasticity and abrasion resistance. At the same time the connection of EVA with the tape showed the minimum result (25.6\%), and therefore the connection is not elastic.

The usage of summer shoes implies legs' mobility, and therefore the shift of materials to each other will be considered an important indicator. The results of the experiment are shown in Figures 4-6.

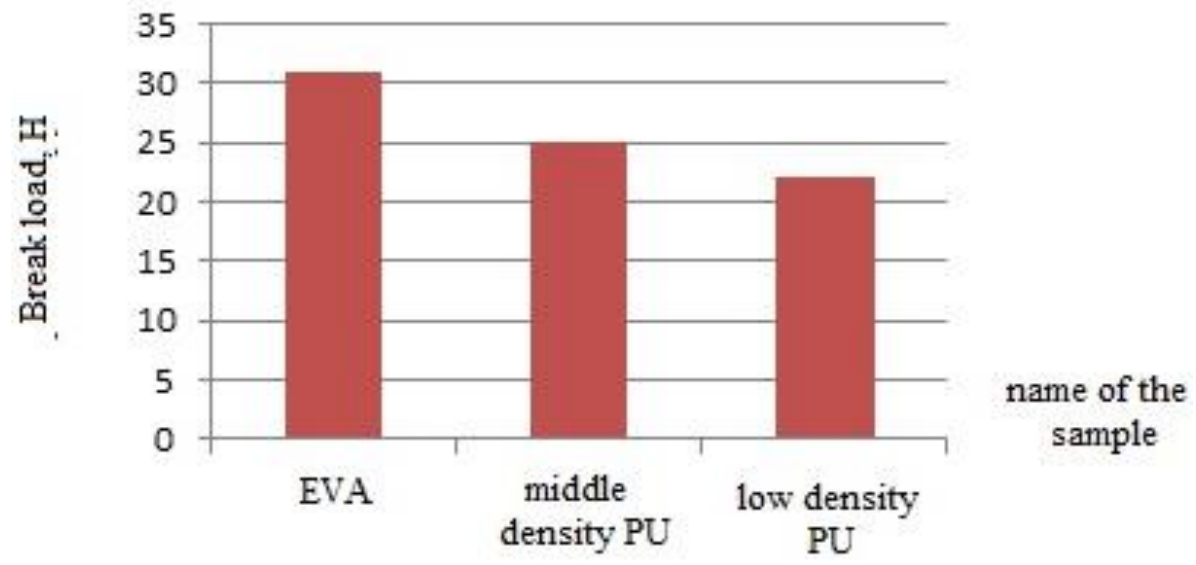

Figure 4. Break load at materials shift (ultrasonic exposure is 2 sec.) 


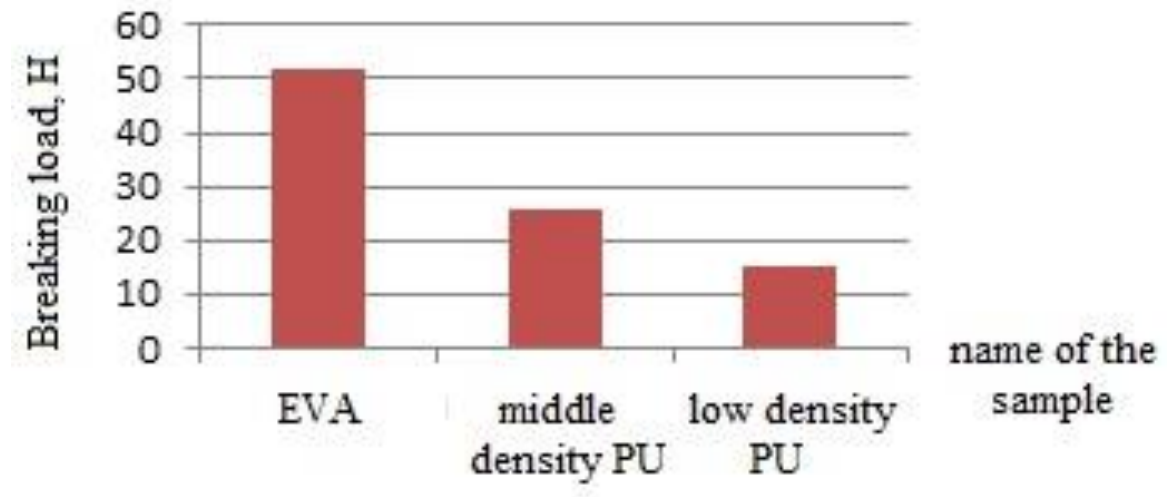

Figure 5. Break load at materials shift (ultrasonic exposure is 3 sec.)

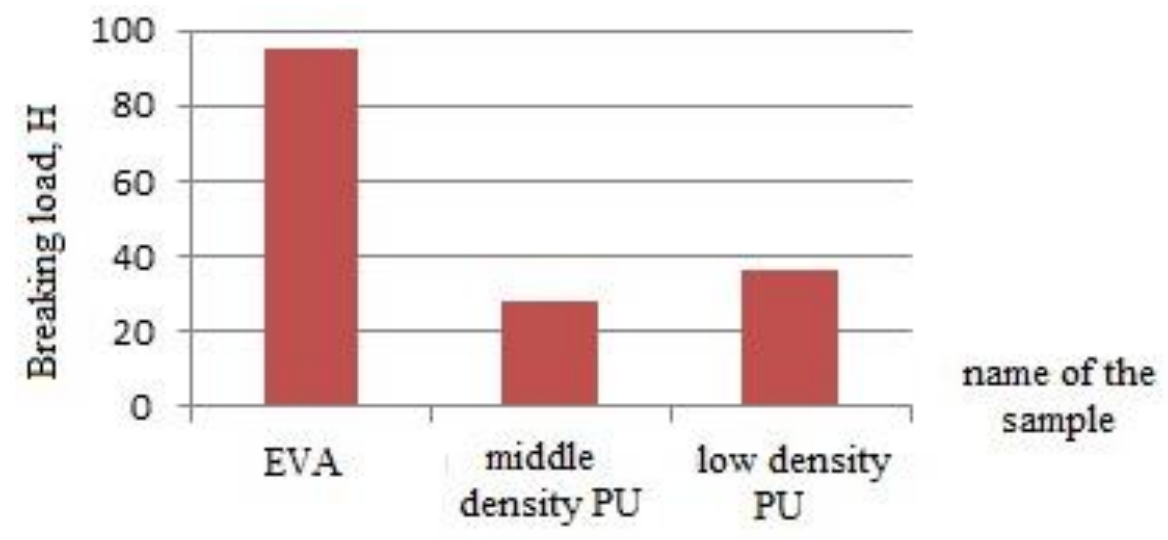

Figure 6. Break load at materials shift (ultrasonic exposure is 3 sec. and with the use of prefastening)

The results of the obtained samples' strength tests made it possible to find out that, in the area where the sound waves effected the technological process of materials used in shoe production welding, the optimal mode is the influence of the ultrasonic wave for 3 seconds in the preliminary fastening.

\section{Conclusion}

Adhesive methods of parts joining are widely used in footwear production. The main qualitative characteristic of shoes is the strength of the sole attachment. However, despite the significant progress observed in recent years in the technology of shoe bottom gluing, the main reason for its premature failure is the soles' unsticking.

Adhesive methods have a number of advantages over other ones, although they are not without drawbacks. One of them is high toxicity of the used raw materials. Environmental requirements do not allow the use of highly active, but at the same time hazardous to health reagents. The choice of adhesives in the footwear industry is limited to the use of low-toxic and less active raw materials when it is necessary to ensure sufficient strength.

Recently, there has been a tendency to improve the joining process using new external influences, such as treatment with steam chemical media, imposition of an external electromagnetic field, treatment in a low-temperature glow discharge plasma.

But the listed methods ask for expensive equipment and qualified specialists.

In this research, it has been suggested to improve the parts joining process using sound effects. 
The purpose of this study was to increase the strength characteristics of ultrasonic joints of summer shoe parts. A set of tests was carried out on the selected samples that made it possible to choose the best material for summer shoes production and the optimal mode of ultrasonic wave operation, which ensures high strength characteristics of the welded joint.

The research results were used at the Taezhnik enterprise (Kazan) that specializes in the manufacture of products intended for use in various climatic conditions, including humid environment (clothes, backpacks, summer, demi-season, winter shoes, accessories for sports, outdoor activities and tourism).

In general, the trends in the production of footwear are moving towards economically justified reduction in batches' amount. Each batch is supposed to take into account different features of the foot shape and even the manufacture of a unique pair for a particular person. Now footwear manufacturers are interested in digitalization and production automation. These are, in particular, issues related to the preparation of technological processes for the manufacture of adhesive shoes, and of course, issues of robotization and automation during adhesion. Modern computer technologies open up wide opportunities for increasing labor productivity and saving materials, and, consequently, solving the problem of the competitiveness of a modern shoe enterprise. Nowadays, automated shoe-making systems offer the widest range of possibilities.

Taking into account the latest developments in the field of textile industry in footwear production, it is possible to achieve high levels of competitiveness due to improved strength characteristics, qualitatively new properties of manufactured shoes and a more favorable cost of products.

\section{References}

Tsobkallo, E.S., Turkina, N.R. (2006) Electron microscopic study of the natural supramolecular structure transformation. Design. Materials. Technology. SPb., No. 1 - 26-29.

Gavrilova, O.E. Nikitina, L.L. (2013) Application of polymer materials to optimize modern technological processes of manufacturing light industry products // Bulletin of the Technological University, 16, 140-151.

Nikitina, L.L., Gavrilova, O.E., Garipova, G.I. (2012) Ensuring the strength of adhesive joints of footwear parts. Bulletin of the Technological University, 24, 100-104.

Dolidze, N.A. Ugrekhelidze, I.I. (2014) Investigation of the strength parameters of the artificial fur welded seam. GIUA Bulletin, 1 58-65.

Abutalipova, L.N., Khairullina, E.R., Khisamieva, L.G., Nurullina, G.N. (2018). Innovations in the production of textile products. Stary Oskol: TNT.

Ryazanov A.V., Davletbaev I.G. (2015) Ultrasound as the main factor in increasing the efficiency of technological processes in the shoe industry Modern trends in science and education: Collection of scientific papers based on the materials of the International Scientific and Practical Conference on February 28, 2015: in 5 parts. Part III. Moscow - 55 p.

Iberall, A. S. (1964) The use of lines of nonextension to improve mobility in full-pressure suits: the research report. Ohio: Aerospace Medical Research Laboratories, Wright-Patterson Air Force Base, - 118 p.

Schrobsdorff, B. (2006) Protective Clothing. Health \& Safety International, 14

Zhuravleva, N. L., Matyuhina N. M. (2011) Improving underwear suit for the space suit. Abstracts of the International Korean-Chinese conference. 
Marreiros, S. S. P. (2010) Skin Strain Field Analysis of the Human Ankle Joint. Lisbon, 73 p.

Newman, D. J. Hoffman, J., Bethke K., Blaya J., Carr C., Pitts B. (2003) An astronaut "Bio-Suit" system: exploration-class missions. NIAC: MIDÉ Technologies, TAI, - $46 \mathrm{p}$.

Nurullina, G.N. (2019) Modern materials and technologies for personal protective equipment against chemical factors. Monograph. Kursk: Publishing house "University Book".

Nurullina, G.N., Bogdanova, V.I., Tukhvatullin, F.G., Nurullin, M.A. (2017) Investigation of the possibility of using wiping materials in the manufacture of protective clothing. Bulletin of Kazan Technological University, 20(20) 72-73. 